\title{
A holistic approach to reduce negative impacts of Hydropeaking
}

\author{
W. Gostner \& C. Lucarelli \\ Patscheider \& Partner Engineers Ltd., Mals, South Tyrol/Italy \\ D. Theiner \\ AF-Colenco Ltd., Baden, Switzerland
}

A. Kager \& G. Premstaller

Sel Plc, Bozen, South Tyrol/Italy

A. J. Schleiss

EPFL ENAC IIC LCH, Station 18, Lausanne/Switzerland

\begin{abstract}
Hydropeaking is a common phenomenon of water courses that are affected by peak energy production of hydro power plants. It may cause severe impacts on the biodiversity of a stream. In fact, due to hydropeaking fishes, macroinvertebrates and aquatic plants undergo a major stress and frequently they are not able to survive these frequent water level fluctuations. In this paper a case study is presented where several mitigation measures for an affected river are evaluated. Abiotic indicators representing the hydropeaking phenomenon and responsible for an impaired biodiversity are calculated and compared. Furthermore a cost-benefit analysis of the mitigation measures is carried out allowing to define the measures to be realized. Facing the challenge of a holistic approach the study is embedded in a project with public participation of all concerned stakeholders addressing also the need of flood protection and ecologically sound river restoration.
\end{abstract}

\section{INTRODUCTION}

\subsection{Motivation of the study}

Hydropeaking is a common problem of water courses that are affected by production of peak energy in hydro power plants. The hydropeaking phenomenon is characterized by rapid changes in discharge (Locher, 2005, Schneider \& Noack, 2009). In order to meet peak electricity demand, hydropower stations alter their discharge several times a day, resulting in the alteration of hydrological characteristics of downstream flow, including magnitude, duration, timing, rate of change (upramping and downramping rate) and frequency of changes in flow (Céréghino \& Lavandier, 1998, Marty et al., 2009).

Hydropeaking may cause severe impacts on the biodiversity of a stream. In fact, due to hydropeaking the abiotic environment in a stream is strongly altered. As a consequence many fishes, macroinvertebrates and aquatic plants undergo a major stress and very often they are not able to survive these frequent water level fluctuations (Vehanen et al., 2003, Meile, 2006).

Water policies, for example the European Water Framework Directive (EU, 2000) require a good ecological status of rivers to be re-established. The Swiss Federal Law for water protection is even more straightforward in forcing the owners of hydropower plants, responsible for hydropeaking, to realize structural or - in exceptional cases - non-structural mitigation measures.

In this paper a case study is presented where different solutions to mitigate the impacts on stream ecology due to hydropeaking are evaluated. With the help of abiotic indicators representing the hydropeaking phenomenon the present status of habitat conditions in the affected river system is examined. By analyzing costs and benefits of technically feasible solutions and judging the effect on river ecology the best variants can be determined. 
In order to provide a holistic understanding, the analysis is deepened with the help of the Gomez and Probst (Gomez \& Probst, 1995) method. This method was developed in order to analyze complex problems including the construction of a network between elements forming the system. However, integrated analysis for problem solving provides only the fundamentals for discussion of the issues in the public. Thus, the present case study was embedded in an integrated river management concept with public participation where other topics like flood protection, aquatic and terrestrial ecology, land use planning were also considered.

\subsection{Physical indicators of hydropeaking}

Due to hydropeaking the hydrological regime of a river is altered with a direct impact on the abiotic environment of a river such as hydraulics and sediment transport. The abiotic environment exerts his impact on the biotic environment of the aquatic system, i.e. on its long term ecological functionality. In order to describe the short term impacts and assess the hypothetical effect of mitigation measures several physical indicators might be used (Schweizer, 2009). They are briefly described here:

- Absolute flow change rate $\left(\mathrm{Q}_{\max / \min }\right)$ : depending on this relation and on the characteristics of the artificially added discharge water temperature and turbidity in the affected river reach might change, causing negative impacts for aquatic animals. However, peak flow $\mathrm{Q}_{\max }$ is responsible for others of the following indicators, too.

- Frequency of bed mobilization: if the river bed is mobilized at each hydropeaking cycle, macroinvertebrates and fish eggs in the hyporheic zone are moved. Consequently, in these river reaches reproduction activity for fishes is barely possible.

- Rate of change on the rising limb of the hydrograph: A too high rate of change causes the drift of macroinvertebrates as there isn't given enough time to them to budge into zones where shear stress is low. This happens rather in channelized rivers than in other river types.

- Rate of change on the falling limb of the hydrograph: this relation influences mainly the variation of river width, but also the variation of flow depth and velocity, creating a stress on aquatic animals. If variation of river width happens too fast, there is the risk that fishes during the decrease of discharge remain in water ponds that are separated from the main flow. In rivers with a natural morphology this risk is higher than in channelized rivers

- Variation of Reynolds number and shear stress: these indicators have a direct influence on the resistivity of macroinvertebrates against being drifted downstream.

For some of these indicators clear quantitative predefinitions and thresholds for ecologically compatible values are available in literature, whereas for other indicators only qualitative considerations can be found.

\subsection{The study area and hydropeaking issues}

The Etsch has its source on the main chain of the Alps closed to the boarder between Italy and Austria and is, in terms of length, the second largest, and, in terms of watershed surface, the third largest river in Italy. Mainly the headwaters of the Etsch are intensively exploited for hydropower production. In the $\mathrm{XX}^{\text {th }}$ century several dams were constructed for the seasonal storage of water in order to produce peak energy.

Table 1. Key data of the Glurns and Kastelbell power plant.

\begin{tabular}{|c|c|c|c|c|}
\hline \multirow[t]{2}{*}{ Plant } & $\begin{array}{l}\text { Net } \\
\text { head }\end{array}$ & $\begin{array}{l}\text { Design } \\
\text { discharge }\end{array}$ & $\begin{array}{l}\text { Installed } \\
\text { capacity }\end{array}$ & $\begin{array}{l}\text { Energy pro } \\
\text { duction/year }\end{array}$ \\
\hline & $\mathrm{m}$ & $\mathrm{m}^{3} / \mathrm{s}$ & MW & $\overline{G W h}$ \\
\hline Glurns & 586 & 18 & 90 & 291 \\
\hline Kastelbell & 294 & 30 & 93 & 438 \\
\hline
\end{tabular}


In the extended project area (Fig. 1) there are two power plants which produce peak energy, namely the power plants of Glurns and Kastelbell. The power plant of Glurns is supplied by water from the Reschen lake that has a reservoir volume of 120 mio. $\mathrm{m}^{3}$. Downstream of the power plant in Glurns there is an intermediate reservoir. From there water is artificially released in order to allow peak production also for the run of river plant in Kastelbell who's water intake is situated around $12.5 \mathrm{~km}$ downstream of the intermediate reservoir, creating hydropeaking effects on the river courses in between. Table 1 reassumes the key data of the Glurns and Kastelbell power plant.

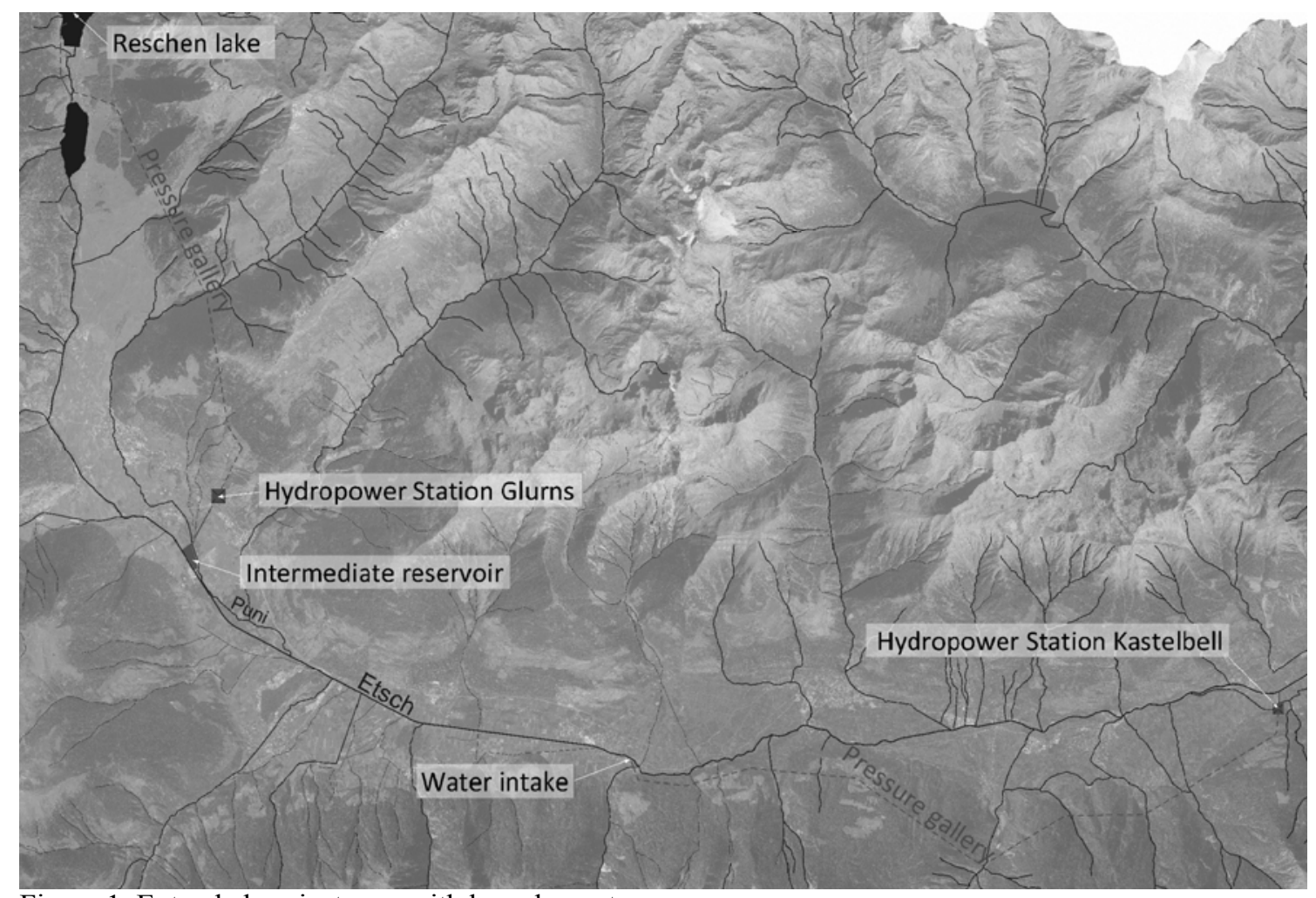

Figure 1. Extended project area with key elements.

Peak energy usually is produced on working days between 8:00 to 18:00. However, in the last years due to changes on the energy market (liberalization, increase in energy demand during weekends) the operation of the plants has undergone some modifications.

In order to follow the daily peak demand, Kastelbell power station that during the night works as run of river plant requires water released from the intermediate reservoir in Glurns. Thus the discharge in the affected rivers Puni and Etsch in the reach between Glurns and Laas is rapidly rising from a low to a high stage corresponding to a flood discharge. When the power stations are turned off, the river discharge returns back to a residual flow, which is often very low because of the large quantities of water that are diverted into the Reschen lake. The result of this operating mode is a high and, more important, rapid variability in flows. Figure 2 shows a typical discharge curve on the Etsch river for a two week period. It can clearly be noticed that there is kind of an artificial flood every day from Monday to Friday due to hydropeaking whereas on the weekends (in the center of the graph) energy need is lower and thus the power stations don't produce peak energy. 


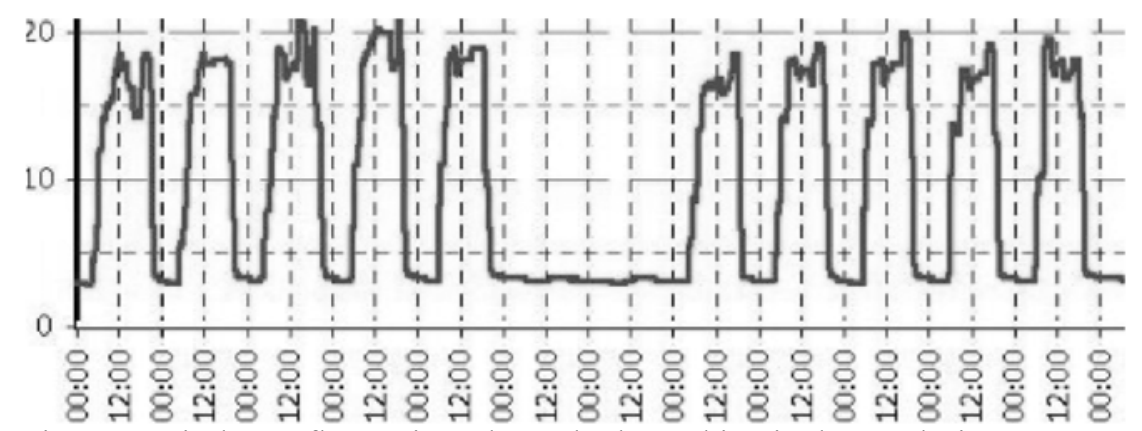

Figure 2. Discharge fluctuations due to hydropeaking in the Etsch river.

There are two rivers affected by hydropeaking in the study area (Fig. 4). From the intermediate basin water is released into the Puni river. After around $3.54 \mathrm{~km}$ of flow length downstream of the point where water is released the Puni confluences with the Etsch river. The length of the Etsch between the confluence of Puni and Etsch and the water intake for the Kastelbell power plant is $8.91 \mathrm{~km}$.

During the years from 1819 to 1825 the Etsch river has been entirely channelized in the project area whereas the Puni river is characterized by a rather natural morphology with diverse habitats that are favorable for the aquatic community (see also Figure 3). When dealing with hydropeaking it is of primary importance to consider also the morphology of the concerned stream. Depending whether the stream is channelized with a regular section or the stream has a natural, pristine morphology the impacts of hydropeaking on the aquatic ecology can be significantly different.

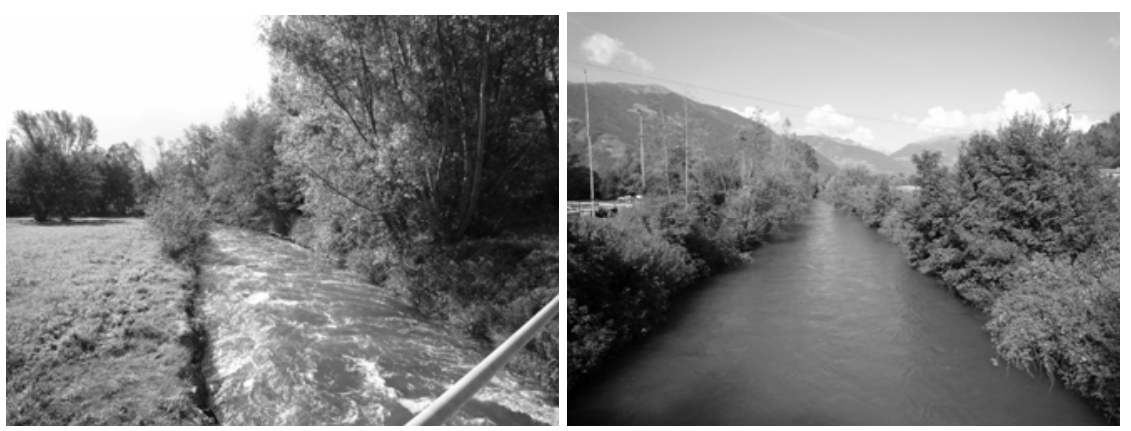

Figure 3. The affected rivers during peak flow due to hydropeaking. Left: Puni (note that hydropeaking causes a discharge almost equal to bank full flow). Right: Etsch (note the artificial river morphology).

\section{CONDUCTED STUDY}

\subsection{Present state}

In order to assess the present state, the following indicators have been considered at three control sections: (i) hydropeaking ratio $\mathrm{Q}_{\max } / \mathrm{Q}_{\min }$, (ii) rate of change on the rising and falling limb of the artificially created hydrographs $(\mathrm{dP} / \mathrm{dt})$, (iii) near bottom shear stress $(\tau)$, (iv) dimensionless critical shear stress $\left(\theta-\theta_{\mathrm{C}}\right)$. The control section P1 (Fig. 4) is situated at the Puni river, the control section P2 at the Etsch river immediately downstream of the confluence with the Puni river, whereas the control section P3 is at the Etsch river around $2 \mathrm{~km}$ downstream of the inflow of the Sulden river which in the study area is the most important tributary of the Etsch. 


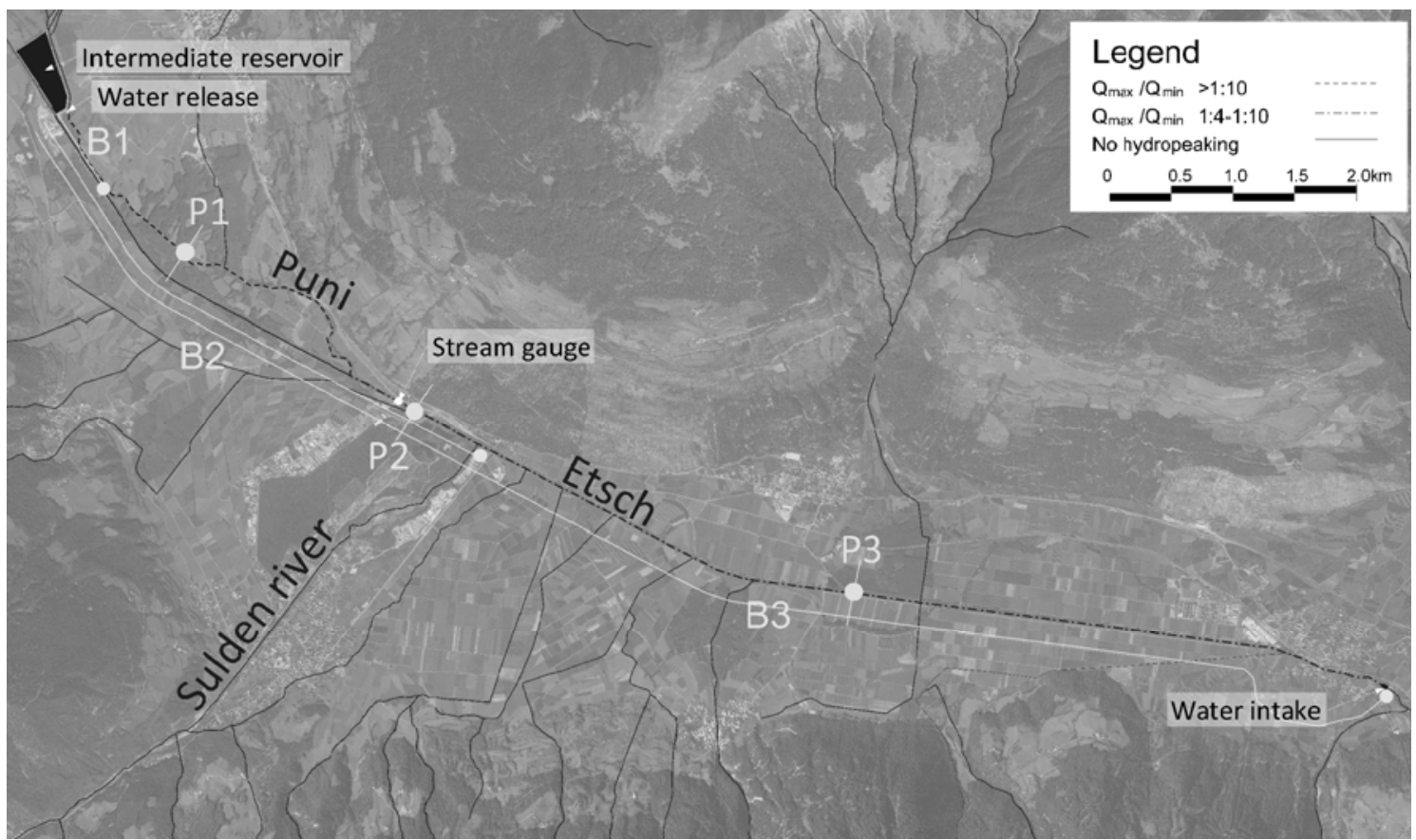

Figure 4. Study area with key elements, control sections P1-P3 and structural project variants B1-B3.

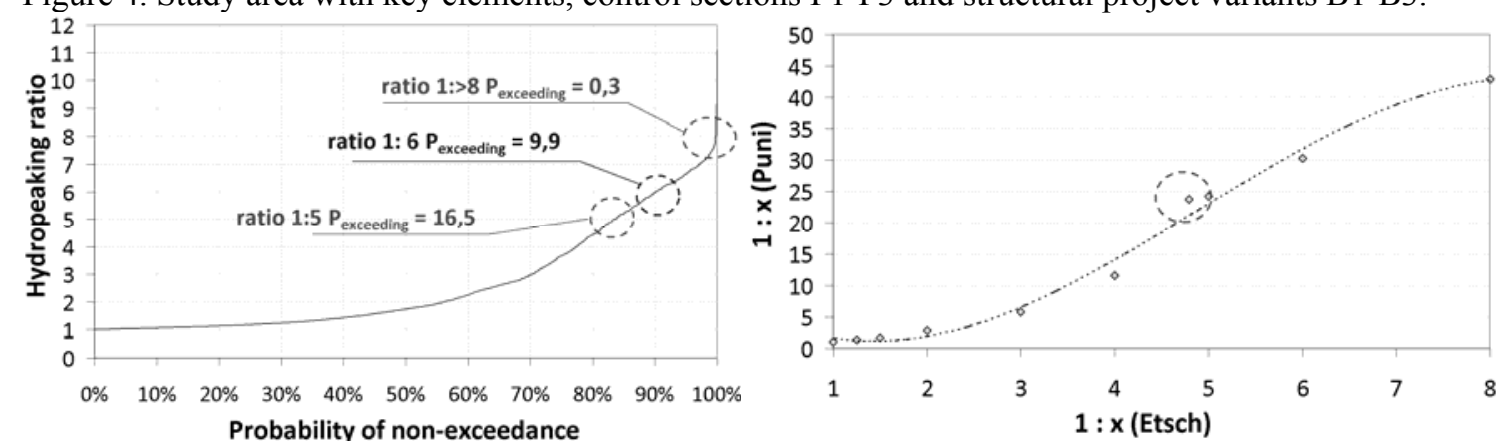

Figure 5. Duration curve for hydropeaking ratio in the Etsch (left) and correlation of hydropeaking ratio between Etsch and Puni.

Analyzing in detail the discharges from 1996 to 2004 at the control section P2 (situated near a gauge station), the duration curve for the hydropeaking ratios $\mathrm{Q}_{\max } / \mathrm{Q}_{\min }$ (Fig. 5) shows that a hydropeaking ratio $>1: 5$ at the Etsch is exceeded for not more than $16.5 \%$ of the time, whereas a hydropeaking ratio $>1: 8$ is an exceptional event that occurs in average once or twice per year. Comparing hydropeaking ratios between river Etsch and river Puni (Fig. 5) it can be concluded that a hydropeaking ratio of 1:5 at the Etsch is corresponding to a ratio of 1:25 at the Puni.

When considering up-ramping and down-ramping rates at the control sections (Fig. 6), it can be observed that at river Puni the change of water depth is $29 \mathrm{~cm} /$ hour at the rising limb of the hydrograph and $58 \mathrm{~cm} /$ hour on the falling limb of the hydrograph, whereas at P2 and P3 these values are slightly lower. In literature different threshold values are given (Saltveit et al., 2001, Halleraker et al., 2002, Baumann, 2004). An average value of $12-18 \mathrm{~cm} /$ hour for the downramping rate is generally seen as an ecologically acceptable value. 

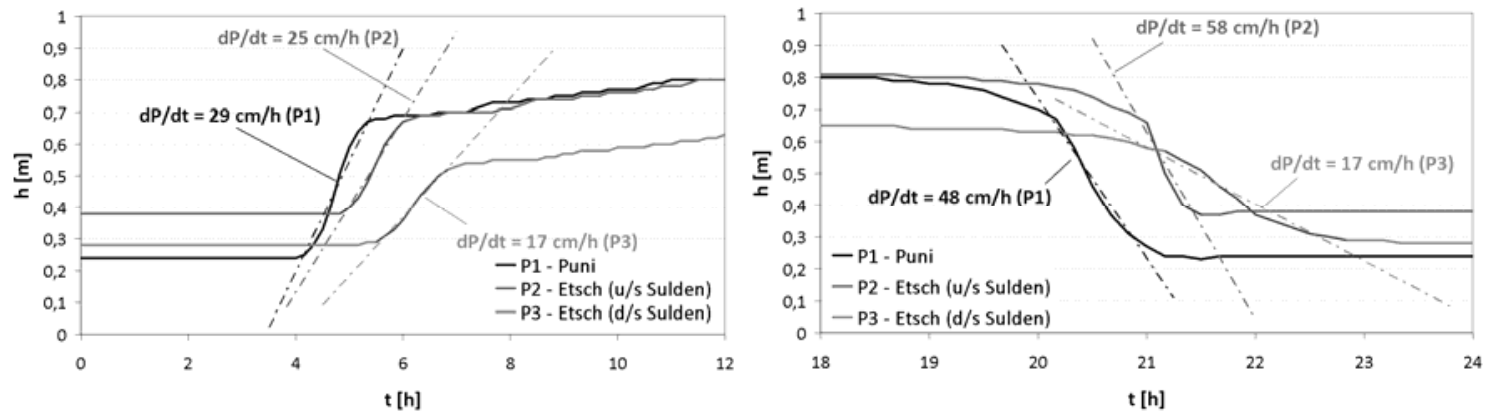

Figure 6. Up-ramping (left) and downramping rate (right) at control sections.
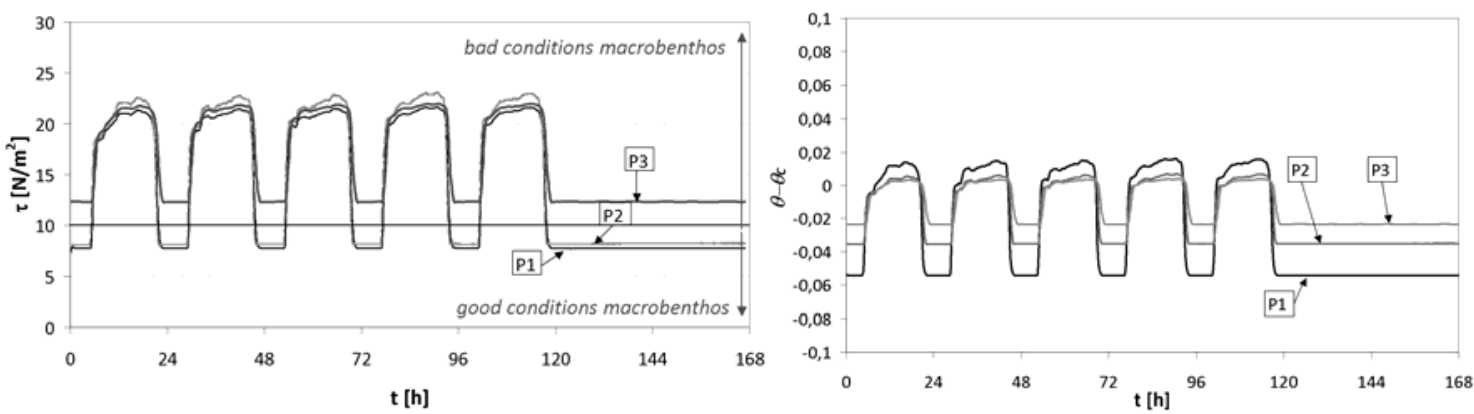

Figure 7. Bottom shear stress (left) and difference of shear stress $\theta$ and critical shear stress $\theta_{c}$ for incipient bed load motion (right).

If bottom shear stress is looked at, in Figure 7 can be seen that during maximum discharges bottom shear stress is always above $10 \mathrm{~N} / \mathrm{m}^{2}$ which in literature (Baumann, 2004, Gibbins et al., 2007) is indicated as maximum tolerable shear stress for most of the macroinvertebrates. The combination of fast up-ramping rates and high bottom shear stresses for macrobenthos in the Puni and Etsch causes life conditions being far from the ideal. However, due to the channelized morphology of the Etsch bottom shear stress is higher than $10 \mathrm{~N} / \mathrm{m}^{2}$ even in low flow conditions.

The right imagine on Figure 7 states that during maximum flow critical shear stress for the commencement of bed mobilization is reached. Therefore additional stress during the spawning season might be caused due to partial movement of the river bed.

The analysis of the present situation allows the conclusion that the rivers in the project area are strongly affected by hydropeaking operations leading to losses in biomass and consequently an impairment of biodiversity. However, mainly in the Etsch also the channelized river morphology is a factor responsible for biodiversity decline. Therefore, mitigation measures to improve the present situation have to be planned considering both hydropeaking and morphology.

\subsection{Definition of mitigation measures}

\subsubsection{General considerations}

Mitigation measures for hydropeaking are subdivided into two concepts, namely operational (non-structural) measures and structural measures. If at the first glance operational measures seem to be realizable quite easy, it is important to be aware that hydropeaking operations are necessary to cover the peak electricity demands. Peak load power plants are, besides gas turbine and pump storage plants, the most effective way to produce peak energy. When a peak load power plant changes its operational rules by reducing hydropeaking in scale and/or time, consequences for national economies are to be faced as other sources have to cover the loss in peak energy production. 


\subsubsection{Operational measures}

For the present case two major groups of operational measures have been considered:

- the complete elimination of peak production in the power plant of Kastelbell (A1) and

- the reduction of the hydropeaking ratio to maximum ratios of 1:4, 1:3, 1:2, 1:1.5 and 1:1.25 (A2).

If peak production in the power plant of Kastelbell was completely given up and from the intermediate basin a constant discharge was released, the power plant in Glurns would also have to modify his operational rules and would reduce drastically the duration of peak production. The volume of the intermediate basin is in fact large enough to temporarily store the water that has been turbined in the power plan of Glurns only for two hours before being filled. Also when hydropeaking ratio is reduced, both power plants have to adapt their operational modes.

\subsubsection{Structural measures}

Several structural measures for the present case were discussed. They focus on realizing an artificial subterranean channel that runs parallel to the affected rivers and transports the hydropeaking discharges downstream. To transport the peak flows of maximum $20 \mathrm{~m}^{3} / \mathrm{s}$ the channel will be realized as a rectangular concrete profile with a width of $7 \mathrm{~m}$ and a height of $3.15 \mathrm{~m}$. The channel will be pressurized, therefore allowing for a low head power plant to be installed at its downstream end. The three variants B1, B2 and B3 (Fig. 4) only differ in the lengths of the channel.

In variant B1 the artificial channel has a length of only $0.5 \mathrm{~km}$. It allows to release water alternatively into the Etsch or into the Puni. At the intermediate reservoir water can only be released into the Puni, because there the river bed of the Etsch is at a higher level than the bottom of the intermediate reservoir. In variant B2 the channel has a length of around $4.5 \mathrm{~km}$ is extended until the mouth of the Sulden river and the water is released at this point into the Etsch. In variant B3 the channel, having a length of $12.5 \mathrm{~km}$, covers the whole length of the study area and releases water directly into the water intake in Laas.

\subsubsection{Cost-benefit analysis}

A cost-benefit analysis has been conducted in order to compare operational with structural measures. When operational measures are adopted, besides of the fact that peak energy has to be provided elsewhere, the plant owner has to face economical losses. A complete elimination of hydropeaking for example would lead to an average loss of selling price of more than $10 \%$ at the Glurns power plant and around $5 \%$ at the Kastelbell power plant. In Figure 8 the cost-benefit analysis is represented graphically. The total abandonment of hydropeaking is taken as reference scenario where the expected losses in 30 years are assigned a value of $100 \%$. For each of the operational measures always two scenarios were calculated: one scenario with the actual volume of the intermediate basin $\left(150.000 \mathrm{~m}^{3}\right)$ and one scenario with the hypothesis that the volume of the intermediate basin is increased to $400.000 \mathrm{~m}^{3}$. The left column beneath the indication of the hydropeaking ration (f.i. 1:2) shows the scenario with the actual volume and the right column with the increased volume of the intermediate basin. The three columns on the right end of the graph show the structural variants B1 to B3. 


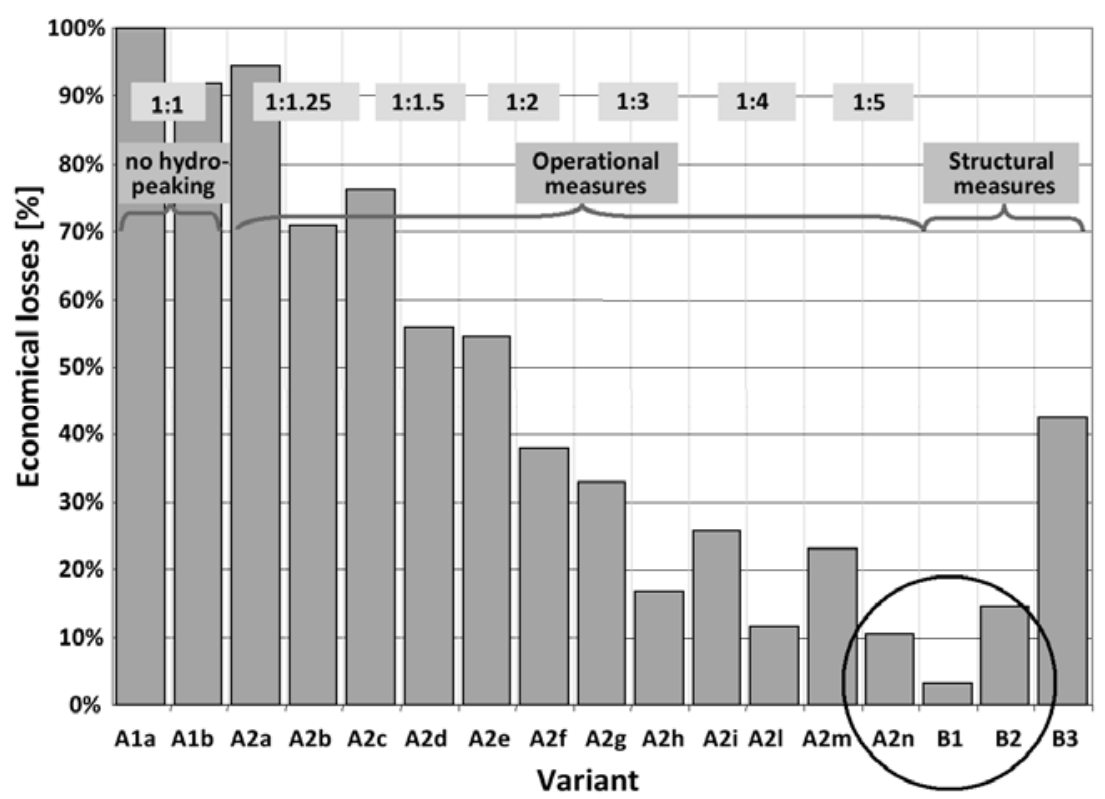

Figure 8. Graphical representation of the cost-benefit analysis

The graph puts in evidence that the variant B1 generates the least economical losses in 30 years (only $3 \%$ of the losses in comparison to a total elimination of hydropeaking). Also variant B2 is an economically valid variant as the economical losses are at a level of around $15 \%$ in comparison to a total hydropeaking abandonment. Concerning the operational measures, it results that after an increase of the volume the intermediate reservoir is suitable for being used as detention reservoir. If hydropeaking ratio is limited to 1:5 in the Etsch river and the volume increased, economical losses are around $10 \%$ in comparison to no hydropeaking.

Consequently, a combination of variant $\mathrm{B} 1$ or $\mathrm{B} 2$ and $\mathrm{A} 2 \mathrm{n}$ is the best solution to mitigate the harmful impacts of hydropeaking without major losses for the plant owner and with an acceptable loss of available peak energy.

\section{DECISION FINDING PROCESS}

\subsection{Establishment of a holistic decision supporting network}

When complex problems have to be solved, holistic and integrated approaches that consider all the critical elements involved in a decision taking process are needed. Mitigation of hydropeaking impacts concerns not only the plant owner, but also different other stakeholders having an interest on a sustainable use of the water resources.

In the present case, the variant analysis described in the preceding chapter, is deepened with the help of the Gomez and Probst (Gomez \& Probst, 1995) method. This method was developed in order to analyze complex problems where a high number of factors with strong interactions and high dynamics are present. The core of the method includes the construction of a network forming the system. The network is set up by defining all the factors that are concerned by a problem, and subsequently establishing where relations between the factors exist and in which way the factors influence each other, i.e. evaluating in a relation which is the influencing (active) element and which is the influenced (passive) element. A matrix is then built, attributing weights to every link, allowing to obtain an integrated view of the functioning of a system.

In an expert assembly a total number of 64 factors that are relevant for the study area have been defined. After establishing direct relations, and also indirect relations of the first and second order, Figure 9 that shows the significance of the considered factors was elaborated. Hydropeaking and peak energy production obtain the highest active sums and are therefore motors of the system. Therefore the decision to analyze in detail hydropeaking in the project area was more than correct. Reactive elements can be used as indicators for the problems created by the 
situation. As expected, biodiversity and cash flow for the plant owner are important variables that are strongly influenced by hydropeaking. Surprisingly, also the attractiveness for tourism is an important reactive element demonstrating that the status of running waters is a key element for the prosperity and image of a region.

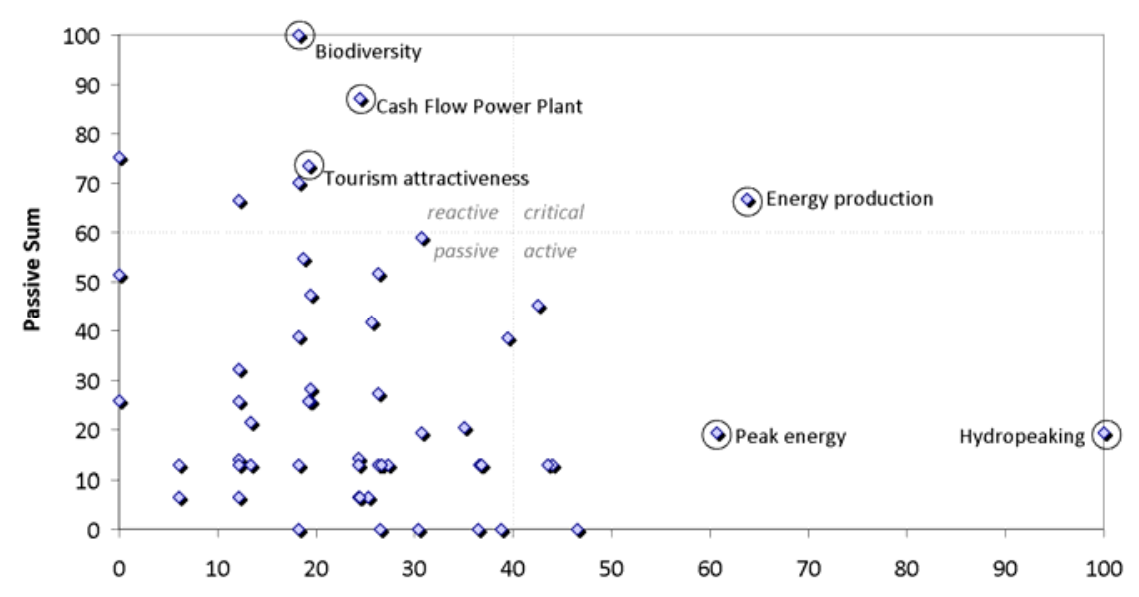

Figure 9. Graphical representation of influence matrix with active, critical, reactive and passive elements.

\subsection{Public participation}

As the issues in the study area are not only limited to hydropeaking, but also to flood protections, to land use management, irrigation for agriculture, tourism, biodiversity conservation and enhancement, in 2008 an integrated river management project was launched with the participation of the concerned stakeholders.

In regular sessions detailed information about ongoing studies was given as a base for working groups where directives for a guiding image ("Leitbild") were elaborated. Also the measures to mitigate hydropeaking impacts were discussed either in working groups or open panel discussions. After the working process the defined measures were approved by the plenum.

\section{CONCLUSION}

The present study shows that hydropeaking causes significant alterations of the abiotic environment. However, evaluation of physical indicators revealed that the strongly altered morphology of the affected water courses also plays in important role for the impaired biodiversity.

In order to define mitigation measures a variant analysis was carried out with the result that operational measures should be adopted in a very limited way as they cause not only economical losses for the plant owner, but also losses of peak energy that has to be produced elsewhere to cover electricity demands. A combination of operational adaptations together with structural measures such as a pressurized conduit running in parallel to the rivers and releasing water at a point where absolute flow rate change might be ecologically acceptable is the solution to be realized.

An integrated decision supporting network clearly showed that hydropeaking is a lever of the system. Therefore, planning and realizing measures to mitigate negative hydropeaking impacts is an important step to allow a sustainable development of the region also in the future. In order to realize the mitigation measures detailed feasibility studies are now on the way. 


\section{ACKNOWLEDGMENTS}

The present study has been carried out within the frame of the integrated river management concept "Flussgebietsplan Oberer Vinschgau" (www.etschdialog.it). It was financed by the plant owner Seledison Plc and by the Public Authority for Water Protection of the Autonomous Province of South Tyrol.

\section{REFERENCES}

Baumann, P. 2004. Revitalisierung und Benthos der Rhone. Schlussbericht SP I-6, Rhone-Thur Projekt, EAWAG, WSL, Limnex AG

Céréghino, R. \& Lavandier, P. 1998. Influence of hypolimnetic hydropeaking on the distribution and population dynamics of Ephemeroptera in a mountain stream. Freshwater biology 40: 385-399.

EU WFD. 2000. Establishing a framework for Community action in the field of water policy. Directive 2000/60/EC of the European Parliament and of the Council of 23 October 2000. The European Parliament and the Council of the European Union.

Gibbins, C.N., Vericat, D. \& Batalla, R.J. 2007. When is stream invertebrate drift catastrophic? Freshwater Biology 52: 2369-2384.

Gomez, P. \& Probst, G. 1995. Die Praxis des ganzheitlichen Problemlösens. Verlag Paul Haupt, Bern.

Halleraker, J.H., Harby, A., Hessevik, T., Saltveit, S.J. 2002. Individual response of juvenile atlantic salmon and brown trout to rapid and frequent flow fluctuations. Abstract, $4^{\text {th }}$ Symp. Ecohydraulics, Cape Town

Marty, J., Smokorowski, K., Power, M. 2009. The influence of fluctuating ramping rates on the food web of boreal rivers. River Research and Applications 25: 962-974

Meile, T. 2006. Hydropeaking on watercourses. Eawag News 61e.

Saltveit, S.J., Haug, I. \& Brittain, J.E. 2001. Invertebrate drift in a glacial river and its non-glacial tributary. Freshwater Biology 46 (12): 1777-1789

Schneider, M. \& Noack, M. 2009. Hydropeaking, environmental impact and mitigation in Germany and Switzerland. Universität Stuttgart, Germany. EnviPeak 24.03.2009, Trondheim.

Schweizer, St. 2009. Bewertung von Schwall/Sunk - Herleitung eines ökologisch abgestützten Bewertungskonzepts. Wasser - Energie - Luft 3: 194-202

Vehanen, T., Huusko, A., Yrjänä, T., Lahti, M. \& Mäki-Petäys, A. 2003. Habitat preference by gray (Thymallus thymallus) in an artificially modified, hydropeaking riverbed: contribution to understand the effectiveness of habitat enhancement measures. J. Appl. Ichthyol. 19:15-20. 